\title{
Digital Inclusion in Older Adults: A Comparison Between Face-to-Face and Blended Digital Literacy Workshops
}

\author{
Claudia I. Martínez-Alcalá ${ }^{1,2 *}$, Alejandra Rosales-Lagarde ${ }^{1,2}$, \\ María de los Ángeles Alonso-Lavernia ${ }^{3}$, José Á. Ramírez-Salvador ${ }^{3}$, \\ Brenda Jiménez-Rodríguez ${ }^{2}$, Rosario M. Cepeda-Rebollar'2, \\ José Sócrates López-Noguerola ${ }^{2}$, María Leticia Bautista-Díaz ${ }^{4}$ and \\ Raúl Azael Agis-Juárez ${ }^{2}$
}

' Cátedras CONACyT, Consejo Nacional de Ciencia y Tecnología, Mexico City, Mexico, ${ }^{2}$ Área Académica de Gerontología, Instituto de Ciencias de la Salud, Universidad Autónoma del Estado de Hidalgo, Pachuca, Mexico, ${ }^{3}$ Área Académica de Computación y Electrónica, Instituto de Ciencias Básicas e Ingeniería, Universidad Autónoma del Estado de Hidalgo, Pachuca, Mexico, ${ }^{4}$ Área Académica de Psicología del Instituto de Ciencias de la Salud, Universidad Autónoma del Estado de Hidalgo, Pachuca, Mexico

\section{OPEN ACCESS}

Edited by:

Dina Di Giacomo,

University of L'Aquila, Italy

Reviewed by:

Andrej Košir,

University of Ljubljana, Slovenia

José Carlos Núñez,

Universidad de Oviedo Mieres, Spain

*Correspondence:

Claudia I. Martínez-Alcalá

c_isabel_alcala@hotmail.com

Specialty section:

This article was submitted to

Human-Media Interaction,

a section of the journal

Frontiers in ICT

Received: 29 November 2017

Accepted: 26 July 2018

Published: 28 August 2018

Citation:

Martínez-Alcalá Cl,

Rosales-Lagarde $A$,

Alonso-Lavernia MÁ,

Ramirez-Salvador JÁ,

Jiménez-Rodríguez $B$,

Cepeda-Rebollar RM,

López-Noguerola JS, Bautista-Díaz ML and Agis-Juárez RA (2018) Digital Inclusion in Older Adults: A

Comparison Between Face-to-Face and Blended Digital Literacy Workshops. Front. ICT 5:21. doi: 10.3389/fict.2018.00021
As information and services are becoming more and more decentralized and they are often available in the cloud, an increasing number of older adults are expected to use Internet-based services - health, education, finance and others. For this reason, it seems important to plan models and/or strategies to allow the older adult population to acquire and enhance digital competencies more easily. The goal of this research is to show a blended workshop based on a Learning Management System (LMS) as a supporting tool for older adults' digital literacy. This blended workshop was based on the adoption of an instructional model and on prior experiences of the groups of elderly that participated in the face-to-face workshops. This study involved 98 adults aged 60 and above, 72 Females $(68.5 \pm 6.9)$ and 26 Males $(73.3 \pm 7.4) .61$ older adults participated in the face-to-face workshop (FFG) on digital literacy and 37 participated in the blended workshop (BLG). Digital literacy increased at the post-evaluation after the workshops but even more for the BLG. Likewise, in the validation of the blended workshop the results were positive regarding ease of use, perceived usefulness, attitude toward using and intention to use, which showed that older adults believe that it is useful to implement this type of supporting systems for developing their digital competencies. Hence, it is possible to conclude that older adults are capable of learning and acquiring digital literacy skills as long as they are strongly motivated or they know the functional benefits related to ICT.

Keywords: digital literacy, older adults, face-to face workshop, blended workshop, learning management system (LSMS)

\section{INTRODUCTION}

At present, Information and Communication Technologies (ICT) are becoming omnipresent in our daily lives due to the increasing tendency to use the Internet and mobile devices such as smartphones and tablets, that have allowed access to information and services anytime, anywhere, thanks to their portability (Navarro et al., 2017; Engel et al., 2018). Consequently, an increasing number of older adults are expected to use Internet-based services-health, education, finance, 
and others- as information and services are becoming more and more decentralized and they are often available in the cloud.

Furthermore, this population has shown considerable interest in learning how to use ICT, to stay socially connected, to access instant information, and to perform everyday tasks such as shopping, traveling, and banking. However, this population's digital skills are minimal, since they are not included in the new interaction environment that marks current technological breakthrough. There is a wide variety of technologies that have caused an increasing gap between the tools used by the young population and the ones used by the elderly population (Vroman et al., 2015; Kuerbis et al., 2017), since the latter are left behind vis-à-vis the rest of the age-groups (Choi and DiNitto, 2013; Hodge et al., 2017).

According to Internet World Stats (2017), from a total of 3.6 billion people worldwide, $48.3 \%$ of the population is digitally excluded. In the case of Mexico, with a total population of 130 , 222, 815, 34.7\% experience digital exclusion. In Mexico, the Instituto Nacional de Estadistica y Geografía (Instituto Nacional de Estadistica y Geografía, 2016) suggests that $78.4 \%$ of adults aged 55 or more do not know or use the Internet.

These disparities regarding Internet and ICT use are commonly referred to as a digital divide, which suggests that people with certain demographic and socioeconomic characteristics can be at a disadvantage to access and use the Internet in comparison with other groups (van Deursen and Helsper, 2015; Delello and McWhorter, 2017; Hodge et al., 2017). Delello and McWhorter (2017) mention that the population with no access to ICT or no interaction with digital products or services is called "digitally excluded." Digital exclusion implies unequal access and incapacity to use the ICT, both of them now considered essential to fully participate in society (Schejter et al., 2015).

It is a fact that constant evolution in ICT brings about the need for people to acquire ever higher levels of digital literacy to maintain their sense of inclusion. Digital literacy is a set of skills associated with the use of ICT that every individual should develop to be able to perform in a computerized society (Friemel, 2016; Van Deursen et al., 2016). Thus, it can be said that digital literacy constitutes a fundamental element in the development of any individual, as it allows its insertion in today's society in a more participatory manner. For this reason, some countries are interested in increasing older adults' digital competencies, as these grant them a variety of advantages and benefits at a personal and social level. It is essential, then, to design strategies that facilitate older adults' participation and presence in the use of Internet-based services.

The following sections constitute a review of how learning occurs in the elderly and the description of educational initiatives that have been implemented for the digital literacy of this population. Firstly, we present two types of learning (face-toface and blended) that were implemented for literacy instruction in older adults within the Institute of Health Sciences of the Autonomous University of the State of Hidalgo. Subsequently, a prior and subsequent comparison of the level of digital literacy obtained by older adults in each modality is made. Next, the validation of the Learning Management System (LMS) implemented within the blended workshop as a support tool for digital literacy of older adults is shown. Finally, the challenges that older adults and instructors face when adopting a mixed workshop for ICT instruction are highlighted.

\section{Education and Learning for the Elderly}

One of the fundamental objectives of this study is to analyze under what learning environment elderly adults learn best, taking into account the bases of andragogy. Andragogy is considered as the discipline that allows to know the most relevant educational principles and processes based on the characteristics and needs of adults, both in their maturity and in their old age (Muchtar and Yanuarsari, 2018). Learning in the elderly presents distinctive features that must be taken into account for any approach to educational programs that include older adults.

In addition to considering the main theories of learning and the pedagogical characteristics applicable to the education of older adults, it is important to highlight other factors that make the teaching-learning process special in the elderly. Some of these factors are: Physical and mental changes, memory loss, decline in cognitive abilities and, finally, life experience. According to Wlodkowsk and Ginsberg (2017), the fundamental element that determines the learning process is motivation, and it should be the main factor in any educational program designed for this type of population.

The fact that older people are often considered dependent and lacking in initiative and determination can lead to education programs being conceived in a condescending manner, from top to bottom, without giving learners any opportunity to set their own priorities and make their own decisions.

There are studies that indicate how the present generations of older adults show the capacity to be active and the interest in increasing the possibilities of human, social and educational development (Oliver et al., 2017; Rubenson, 2018). In this sense, Rubenson (2018) demonstrated that the present generation of older adults wishes to continue education, they have a greater commitment to learning and are aware that through education they can improve their quality of life and their participation in the communities.

Gonzalez et al. (2015) point out that some fundamental aspects for the learning process in older adults are: motivation, experience, need, self-concept, learning usefulness and orientation to learn.

In addition, it is important to consider that learning is not only carried out in classrooms or other formal contexts, but also under many and varied conditions. Above all, the elderly have accumulated a countless number of hours of informal learning. So, it is not enough that older people are given access to existing services, it is also important to create educational environments that recognize and support all types of learning and all types of previous experience (Hodge et al., 2017; Tam, 2018).

Fausset et al. (2013) mention that when older adults notice personally relevant usefulness of technologies, and when, at the same time, they receive family support, they will regularly use and adopt ICT. Therefore, gaining greater understanding of the experience lived by older adults in the use of technology will facilitate the implementation of appropriate technological 
solutions for this population. That is why some authors suggest that ICT patterns of use in older adults should be studied (Tennant et al., 2015; Tsai et al., 2015) and that it is necessary to point out the importance of researching and proposing models and/or strategies for this population to acquire digital competencies more easily.

Therefore, the educational model toward digital literacy of the elderly should be based on 4 important points:

- Usefulness of Learning. The knowledge of ICT provided to the elderly must be really useful, and for that it must respond to the personal and social needs of the latter.

- Cooperativeness and collaboration. The teaching of ICT should focus on teamwork, support, cohesion and interaction to achieve more proactive learning.

- Fostering social inclusion. The knowledge acquired should offer older adults the possibility of expanding communication channels through the web with their relatives and friends, either close or distant.

- Promoting autonomy. Older adults must be the protagonists of their own learning. For this purpose, content must be designed considering the learning styles, interests and expectations of the senescent individual.

In relation to the above, it can be said that the educational model for digital literacy of the elderly should be developed in the framework of a personalized, cooperative, collaborative and meaningful learning, which can provide them with the basic tools as a starting point, and with a source of motivation so that they adopt ICT as part of their life. Likewise, this should be based on andragogy, taking into consideration the biological, psychological and social characteristics typical of their age.

Finally, the teacher is a fundamental element in any teachinglearning process, especially in the case of elderly learning, where the teacher plays an essential role to achieve balance among the student, the group and their needs, and to maintain or increase their motivation, which is essential for the training of older adults. One of the strategies implemented in this study was that the digital literacy workshops had a tutor with knowledge about andragogy, as well as support staff who were gerontology students.

\section{Digital Literacy Workshops for Older Adults}

Due to an increase in recent technology, public institutions and international organizations have been obliged to develop initiatives for the inclusion of older people in the use of ICTs. Table 1 describes some initiatives that have been implemented in the world, to help older adults to be included in today's digital society.

One of the fundamental objectives of digital literacy in older adults is that they take on a more participatory role in society, and hence improve their quality of life. In this sense, the studies mentioned above sought to implement initiatives that allowed the development of digital competencies in older adults, through the creation of face-to-face courses. However, this type of courses presents some limitations that could affect learning in the elderly; for example, working methods in face-to-face courses are not focused on the particular needs of students, and there is no availability of learning materials for consulting outside of class.

\section{MATERIALS AND METHODS}

\section{Context}

The Academic Area of Gerontology at the Instituto de Ciencias de la salud (ICSa) of the Universidad Autónoma del Estado de Hidalgo began to teach the Digital Literacy Workshop for adults over 60 years of age in 2014 and, from the outset, the educational strategy was based on gerontological foundations and andragogy. Six workshops have been delivered to date, with groups of between 15 and 25 older adults.

The diffusion of the workshops is done through printed (advertisements) and digital (radio) media. Older adults enroll in the workshop voluntarily. The workshops last $\sim 4$ months and they are carried out in computer rooms equipped with All-One computers connected to Internet. Every older adult is provided with a printed manual with information on the modules and topics addressed during the workshops. A tutor leads every workshop and s/he indicates the topics to be developed. Moreover, the workshops are supported by professional staff (gerontologists) who provide personalized attention to every older adult.

The digital competencies of each adult are evaluated by a Test which is described below and which is systematically implemented in all the workshops (pre and post). The participants were included in the study as long as they had little or no knowledge of ICT, they were healthy, they could read, write and speak, and were over 60 years of age. Finally, it is important to mention that this study was reviewed and approved by the Investigation and Ethics committee of the ICSa, UAEH. All research participants provided their written and informed consent.

\section{Participants of the Workshops}

This study involved 98 adults, 72 Females $(68.5 \pm 6.9)$ and 26 Males $(73.3 \pm 7.4)$. Sixty-one older adults participated in the face-to-face workshop group (FFG) on digital literacy and 37 participated in the blended workshop group (BLG). The group of older adults who interacted in the face-to-face workshop on digital literacy was composed of 46 women and 15 men, with an average age of $69.54 \pm 7$ years and an average schooling of $8.26 \pm 3$ years. The group of older adults who interacted with the blended workshop was composed of 26 women and 11 men, with an average age of 70.43 years \pm 7 and an average schooling of 9.9 \pm 4 years.

\section{Digital Literacy Workshops Face-to-Face Workshops}

The objective of these workshops was to assist older adults with the development of digital literacy skills through face-to-face tutoring. The face-to-face workshop consists of 3 lessons, namely, Introduction to ICT, Computer Programs and Getting to Know the Internet, with a total of 16 topics.

Regarding learning methods, each student had a printed manual with the topics that would be studied in the workshop. 
TABLE 1 | Description of initiatives for digital literacy of older adults.

\begin{tabular}{|c|c|c|c|}
\hline Source & Description of initiative & Directed to & Country \\
\hline Community Grants Hub (2017) & $\begin{array}{l}\text { Digital Literacy for Older Australians (DLOA): } \\
\text { Australian Government initiative which aims to } \\
\text { improve the digital skills, confidence and online } \\
\text { safety of older Australians in using digital technology. }\end{array}$ & $\begin{array}{l}\text { DLOA targets people aged } 50 \text { years and over who have not } \\
\text { engaged with digital technology or who have limited engagement, } \\
\text { particularly those aged } 65 \text { years and over who do not consider } \\
\text { digital technology as being relevant to their lives and are not } \\
\text { attracted by technological tools. }\end{array}$ & Australia \\
\hline Abad (2014) & $\begin{array}{l}\text { Grandparents and grandsons is the name of one } \\
\text { interesting project related to these initiatives, it is } \\
\text { financed by the European Commission, the aims of } \\
\text { this project is to guide in the use of internet and } \\
\text { email for older adults. }\end{array}$ & $\begin{array}{l}\text { There workshops are aimed to adults with } 55 \text { years as the } \\
\text { minimum age, and it involve the participation of students as a } \\
\text { digital facilitator role and they provide one-to-one support to adults }\end{array}$ & Spain \\
\hline Vas Patricio and Osorio (2011) & $\begin{array}{l}\text { Organized training activities with the use of } \\
\text { Information and Communications Technology (ICT) } \\
\text { for children and older adults }\end{array}$ & Children and older adults & Portugal \\
\hline Ordoñez et al. (2010) & $\begin{array}{l}\text { A computer learning workshop named "Idosos } \\
\text { On-Line" (Elderly Online). }\end{array}$ & 22 older adults completed the computer training workshop & Brazil \\
\hline Moreno Ramírez et al. (2009) & $\begin{array}{l}\text { The Autonomous University of Baja California in } \\
\text { Mexico created the course named "Introduction to } \\
\text { Information Technologies for Older in Plenitude"; } \\
\text { professors of Informatics Degree designed it with } \\
\text { the objective to provide the necessary basis to older } \\
\text { adults for using the computer. }\end{array}$ & $\begin{array}{l}\text { The course has benefited a total of } 92 \text { older adults and it is held } \\
\text { twice a year in a 1-month each training course }\end{array}$ & Mexico \\
\hline Boarini et al. (2006) & $\begin{array}{l}\text { National University of Rio Cuarto in Argentina } \\
\text { created the "Computing Workshop," which aims to } \\
\text { train the older adult to send emails and to use the } \\
\text { browsers. Around } 25 \text { older adults attended this } \\
\text { workshop and the subscription process was on site. }\end{array}$ & These workshops are aimed to older adults & Argentina \\
\hline
\end{tabular}

For the instruction of digital skills, the tutor used digital presentations and a projector as support material. At the beginning of each class, the tutor asked random questions to each student so that they could remember the concepts and topics seen in the previous classes.

\section{Blended Workshops Based on a Learning Management System}

The objective of these workshops was to assist older adults with the development of digital literacy skills, through the presentation of multimedia learning activities and materials that enhance their knowledge. The blended workshop consists of 3 lessons, namely, Introduction to ICT, Computer Programs and Getting to Know the Internet, with a total of 16 topics. The blended workshop organization contains the following labels: Welcome, Lessons, Resources, Chat, Course Outline, Learners and Facilitators (see Figure 1).

Regarding learning methods, the lesson sequence was organized in initiation, development and closure activities. In the initiation activity, the learner has to identify and activate background knowledge. Afterwards, during the development activity new learning is generated. Lastly, the closure activity reinforces learning by suggesting a review of the topics. Also, this workshop had 8 evaluations that allowed older adults to review the concepts at different times (up to 10 attempts), with the aim of reinforcing the knowledge of certain terms and tasks that were seen in each workshop module.
Learners had guides, activities, multimedia learning materials (digital presentations, videos, web pages) and resources that allowed them to acquire the necessary knowledge. Some materials could be viewed within the platform and others were distributed through links or they could even be downloaded for local reproduction on the equipment. It is important to mention that in this workshop both the teacher and the student worked together to build knowledge, generate learning and develop digital skills more easily.

The platform selected for the workshop implementation was NEO LMS, since the integration of administration and management tools facilitate the instructor's work in controlling the development of the course. Furthermore, it is endowed with communication tools that significantly enable course monitoring and development. Additionally, this platform has a version that is adaptable to mobile devices, enabling users to access the platform from any mobile device, any time. Clearly, one of the advantages of a LMS is the possibility of keeping available all the resources and files as often as necessary (Queiruga-Dios et al., 2015).

\section{Instructional Model}

For this study, the ASSURE instructional design model was used, since it has the necessary characteristics to implement face-to face and blended instruction, and it can be adapted to design a course or a lesson systematically on a specific topic (Lopez-Betancourt and Garcia Rodriguez, 2015). In the ASSURE instructional model 6 phases are presented: Analyze learners, State objectives, Select instructional methods and materials, Utilize materials, Require learner response, and Evaluation and revision. 




B



\section{Instruments}

The "Senior Digital Literacy Evaluation (SDLE)" is an instrument that was designed to measure the digital literacy level and it is based on previous questionnaires (Rangel and Peñalosa, 2013; Hall et al., 2014; Cabezas et al., 2017). On the basis of this, one of the authors (CIMA) designed an adapted version of the instrument, thanks to her education as a doctor in Multimedia Engineering. The result is the SDLE test which contains 110 items divided into three sections: Use and knowledge of the computer, Use and knowledge of the Internet and Knowledge of domestic and daily life devices (see Supplemental Material).

The Use and Knowledge of the Computer section includes 54 items divided into four dimensions: (1) Ownership and use of technological and computer devices; (2) Knowledge of computer resources; (3) Identification of computer terms, and (4) Activities normally performed with technological devices. The Use and 
Knowledge of the Internet section includes 44 items divided into three dimensions: (1) Use of Internet resources; (2) Identification of terms related to the Internet, and (3) Activities normally performed with the Internet. Finally, the section of Knowledge of domestic and daily life devices includes 12 items related to the use and frequency of domestic and daily life devices.

The main variables explored were related to ICT use, access, possession, activities, number of times and level of management, along with sociodemographic variables. The score an older adult can obtain in the Evaluation in its Spanish letter is: A+ (Total competence); A (Moderate competence); +M (Medium competence); M (Medium-Low competence); +B (Low-Medium competence) or B (Low competence). These scores are only indicative and it is not possible to assert that the scale provides absolute digital literacy values, but it presents specific and significant indicators of the technological competencies of older adults (Cepeda-Rebollar, 2016).

Likewise, at the end of the blended workshop a validation test was applied based on the Technology Acceptance Model (TAM). In order to validate this workshop, different variables were considered such as perceived ease of use, perceived usefulness, attitude toward using and intended use. The scale corresponds to a five-point Likert scale. The values assigned were: $1=$ strongly disagree, $2=$ disagree, $3=$ neutral, $4=$ agree, and $5=$ strongly agree. Lastly, an open time to older adults was allowed to express their experiences and perceptions about the blended workshop (see Supplemental Material).

\section{Content Validity Analysis}

The validity of an instrument refers to its ability to measure and describe what it is supposed to measure and describe. In particular, content validity aims to verify the degree to which an instrument reflects a specific domain of content of what is measured, that is, the degree to which the measurement represents the measured concept. For validating the Senior Digital Literacy Evaluation (SDLE), content validity methodology was used, in order to determine whether the items or questions proposed in the instrument reflect the knowledge, abilities and skills that we want to measure, in this case the Technological Literacy Level in the elderly.

Content validity is usually evaluated through a panel or an expert judgment, which is defined as an informed opinion of people with experience in the subject, who are recognized by others as qualified experts, and who can provide information, evidence and judgment (Almanasreh et al., 2018). Content validity was carried out with the aid of a group of experts, who evaluated individually every single test item, so as to determine its relevance for the variable it is intended to measure and consequently to verify how adequate the instrument was according to their judgment.

This evaluation was carried out in the second semester of 2014, by a group of 7 experts in the area (5 female 2 male) who have a doctoral degree. These experts undertook the task of evaluating the content validity and the relevance of the instrument. Below, the experts' academic and professional profiles are briefly described:
- Expert 1. Research Professor at the Polytechnic Institute of Leiria, Portugal, with a PhD in Multimedia Engineering from the Polytechnic University of Catalonia.

- Expert 2. Microsoft Technologies Consultant, with a Master's Degree in Information Technology for Education from the Autonomous University of the State of Hidalgo.

- Expert 3. Research Professor at the Autonomous University of the State of Hidalgo. Current Coordinator of the Master's Degree in Information Technology for Education.

- Expert 4. Information Technology Developer in a private company with a $\mathrm{PhD}$ in Multimedia Engineering from the Polytechnic University of Catalonia.

- Expert 5. Research Professor and Master's Degree in Information Technology for Education from the Autonomous University of the State of Hidalgo.

- Expert 6. Research Professor at the Autonomous University of the State of Hidalgo. She is currently carrying out studies on Higher Education.

- Expert 7. Research Professor at the Autonomous University of the State of Hidalgo. She is currently carrying out studies on Andragogy.

Every expert was given a questionnaire which included directions and the conceptual definition of the construct. The options available to classify each item were: (1) essential, (2) useful but not essential, and (3) non-essential. The initial instrument was composed of 145 items represented in three sections. Table 2 describes the constructs, conceptual definition, dimension, items, and total number of items.

Subsequently, every expert determined content validity ratio (CVR and CRV') for each of the items, by means of the equations described in Lawshe and Tristan's Model. Results showed that the majority of items are considered acceptable, given that the values exceed the minimum cut-off point of 0.58 .

Based on the results obtained, items of the instrument were eliminated in those cases where their value was lower than 0.58 . All those items in which the value exceeded the minimum cutoff point of 0.58 were kept. A total of 35 items, which were considered irrelevant by the panel of experts, were eliminated. In the final version, the instrument consisted of 110 items (see Tables 3, 4).

The content value analysis of the items incorporated in the instrument revealed which items are considered relevant for the evaluation of technological literacy level in older adults. In general, the results of the index show that the SDLE instrument can be considered valid in its content.

\section{Statistical Analysis}

It is known that in Mexico there is a $25 \%$ of analphabetism among older adults (Consejo Nacional de Población (CONAPO), 2010), so Pearson correlations were made between age and years of education for each group. Likewise, Spearman correlations between age and the scores of the pre SDLE; and years of education and the scores of the pre SDLE for each group were done, because negative associations between age and digitalization and positive ones between education and digitalization could be expected. Also, the comparison between 
TABLE 2 | Definition and operationalization of each construct included in the Test SDLE.

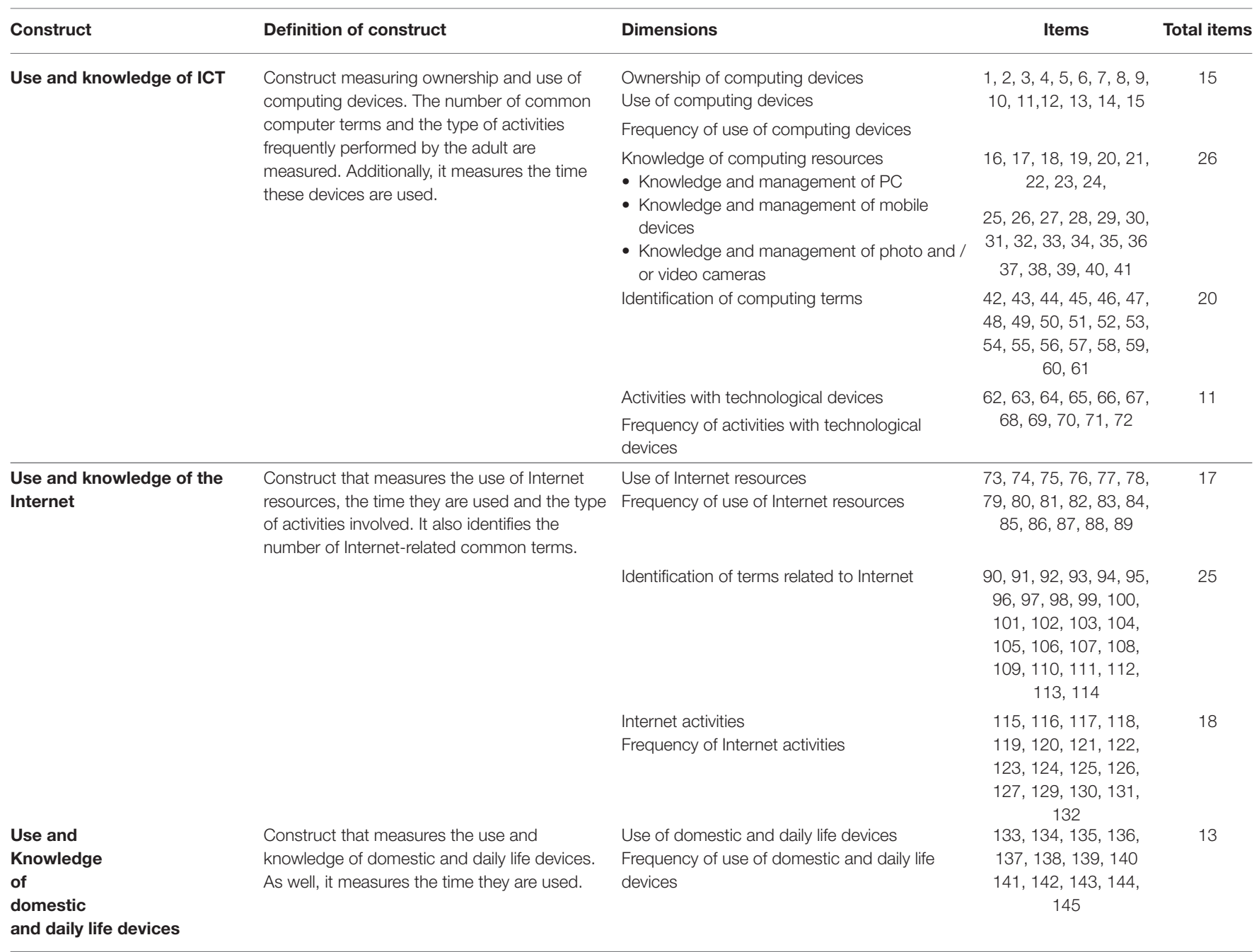

years of education and the post SDLE was made for each group to notice if changes in this relationship occurred. To verify if the FFG and BLG for the variables age and years of education were similar, independent Student $t$-tests were used. Later, pre and Post SDLE scores were compared using Wilcoxon $t$-tests for each group. At last, to find if FFG and BLG were initially different and/or after the intervention, Mann-Whitney $U$ tests were employed. At the end, correlation analyses were carried out to verify if the cumulative number of correct answers on the eight evaluations was related to the final examination score; also, the number of attempts of the participants in each activity was associated to the cumulative number of correct answers on the eight evaluations and the final examination score.

\section{RESULTS}

\section{Comparison Within and Between the Workshops}

Age and education were inversely correlated but not in a significant way in any group $\left[r_{(59)}=-0.16, p<0.21\right.$; $\left.r_{(35)}=-0.26, p<0.11\right]$, for the FFG and the BLG, respectively].
Neither between age and the pre FFG SDLE scores, nor between age and the pre BLG SDLE scores $(r=-0.17, p>0.10$; $r=-0.01, p>0.10$, respectively). Nevertheless, a positive correlation between years of education and the pre SDLE scores was found for the FFG and a marginal one for the BLG $(r=0.53$, $p<0.01 ; r=0.34, p<0.05$, respectively). Likewise, as it can be seen in Figure 2, a positive correlation was found between years of education and the pre and likewise for education and the post SDLE scores only for the FFG $(r=0.53, p<0.01)$; for the BLG $(r=0.16, p>0.10)$.

There were not significant differences in Student $t$-tests for age $\left[t_{(96)}=0.58, p<0.54\right]$. Nevertheless, the level of education was almost 2 years different between groups $[M=8.2 \pm 3$ vs. $M=9.9$ \pm 4 for the FFG and the BLG, respectively; $t_{(96)}=2.19, p<0.03$ ] because the FFG had a lower level of education in comparison to the BLG.

When pre-post comparisons were made within each group with Wilcoxon tests, it was evident that the workshops ameliorated the older adult digital competence in both groups $(z=-6.79, p<0.0001 ; z=-5.30, p<0.0001$, for the FFG and the BLG, respectively). Also, their previous level of 
TABLE 3 | Reason for content validity of the SDLE.

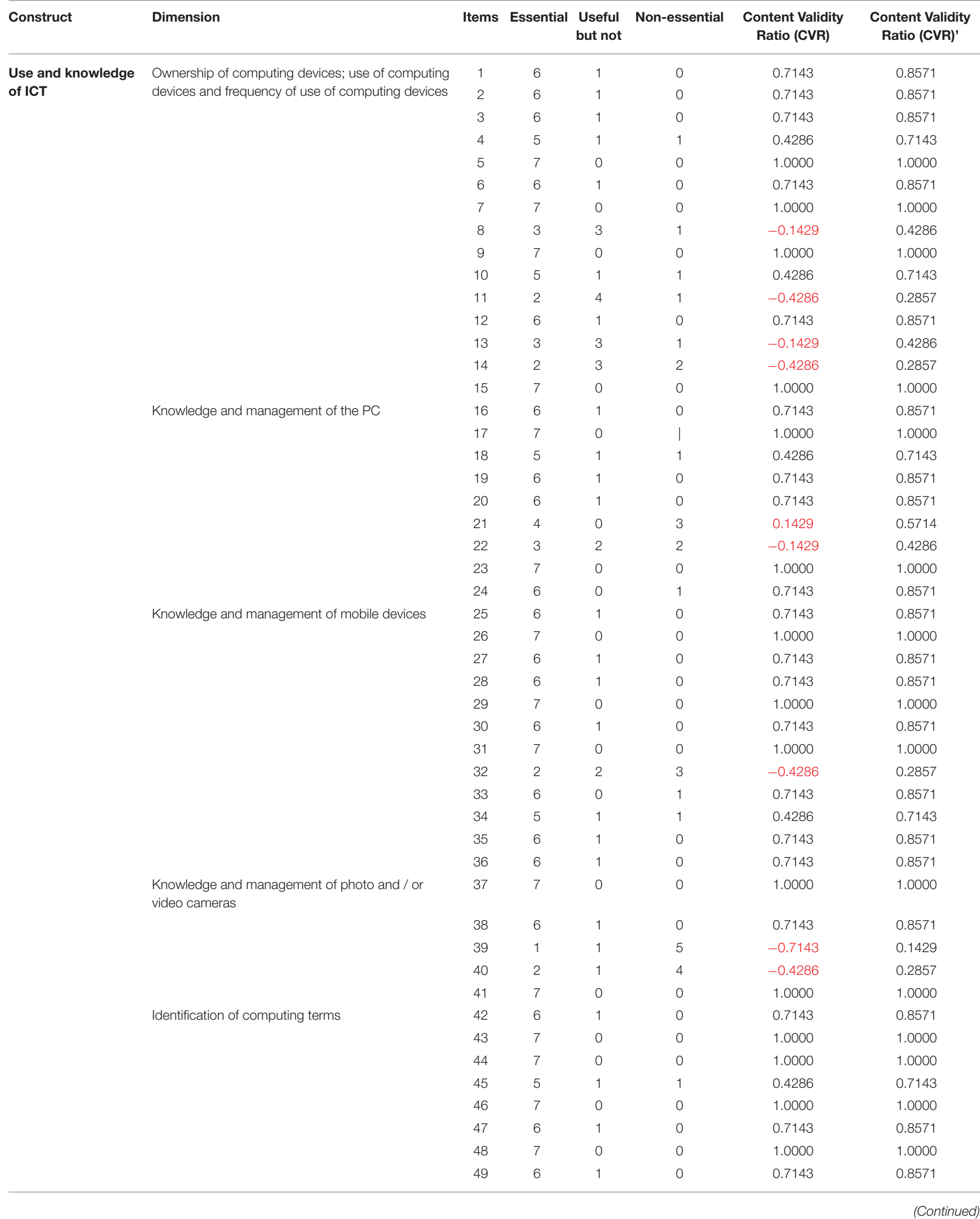


TABLE 3 | Continued

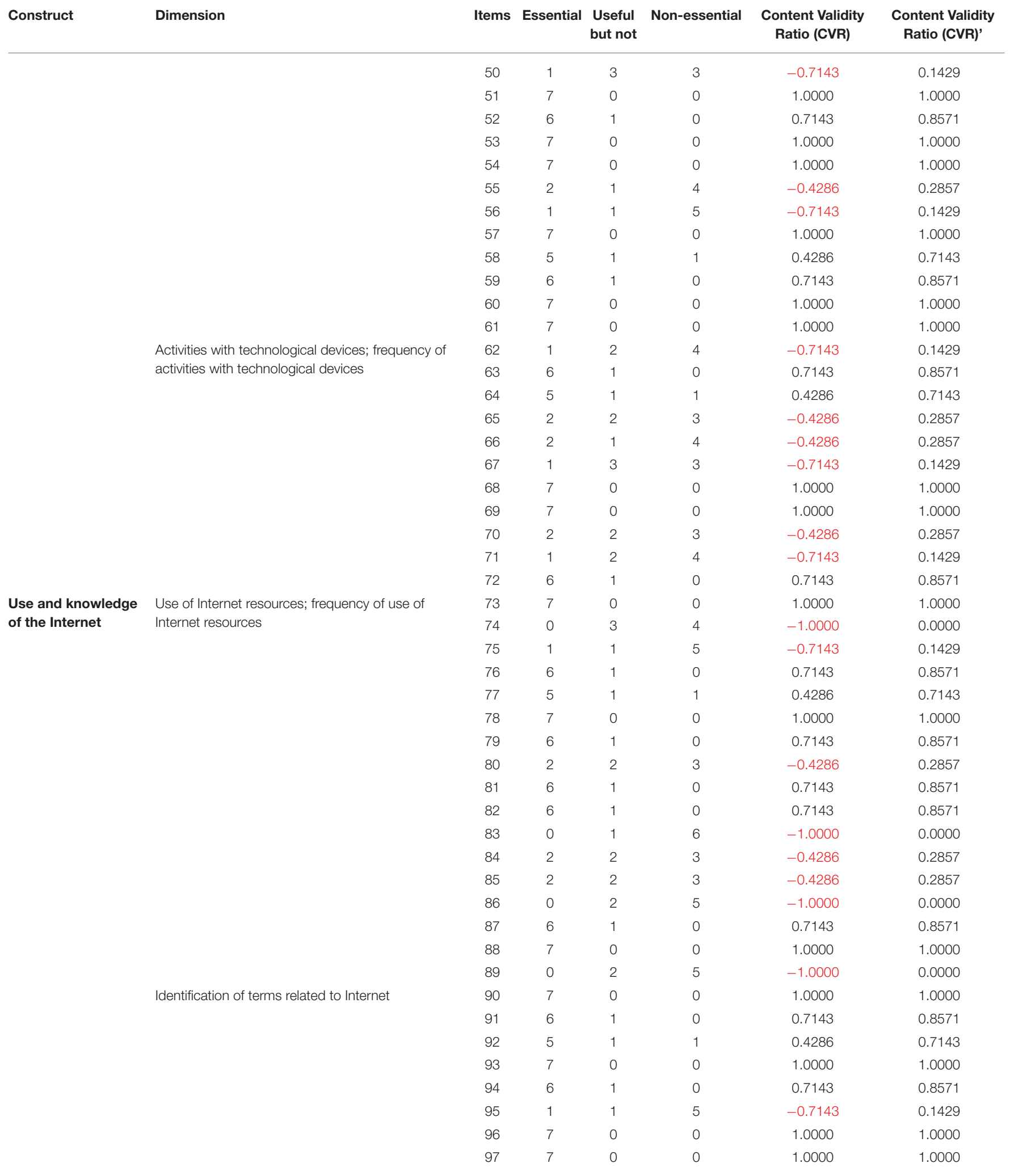


TABLE 3 | Continued

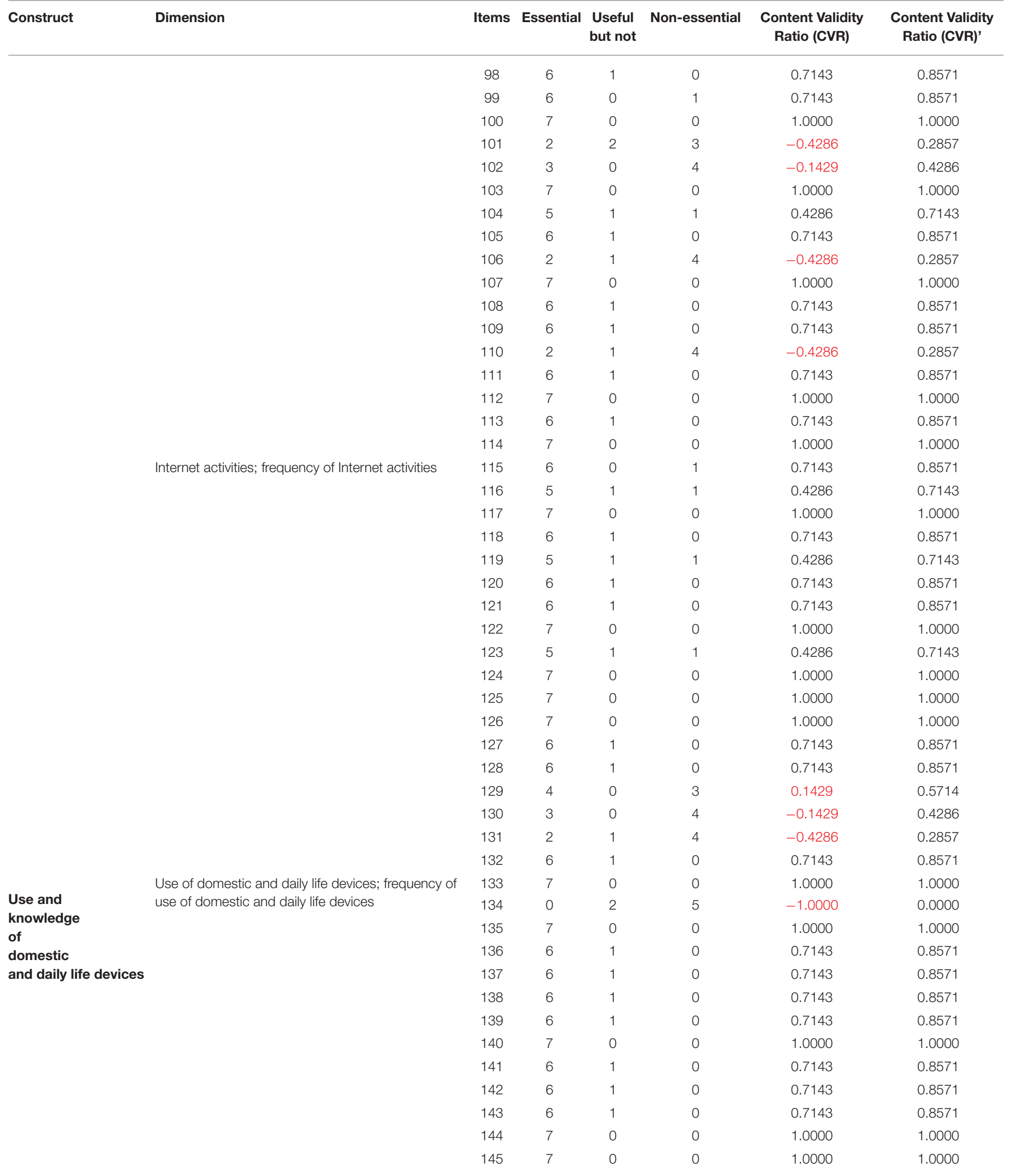

The red colored values indicate that the item does not have content validity. 
TABLE 4 | Final Version of the Instrument SDLE.

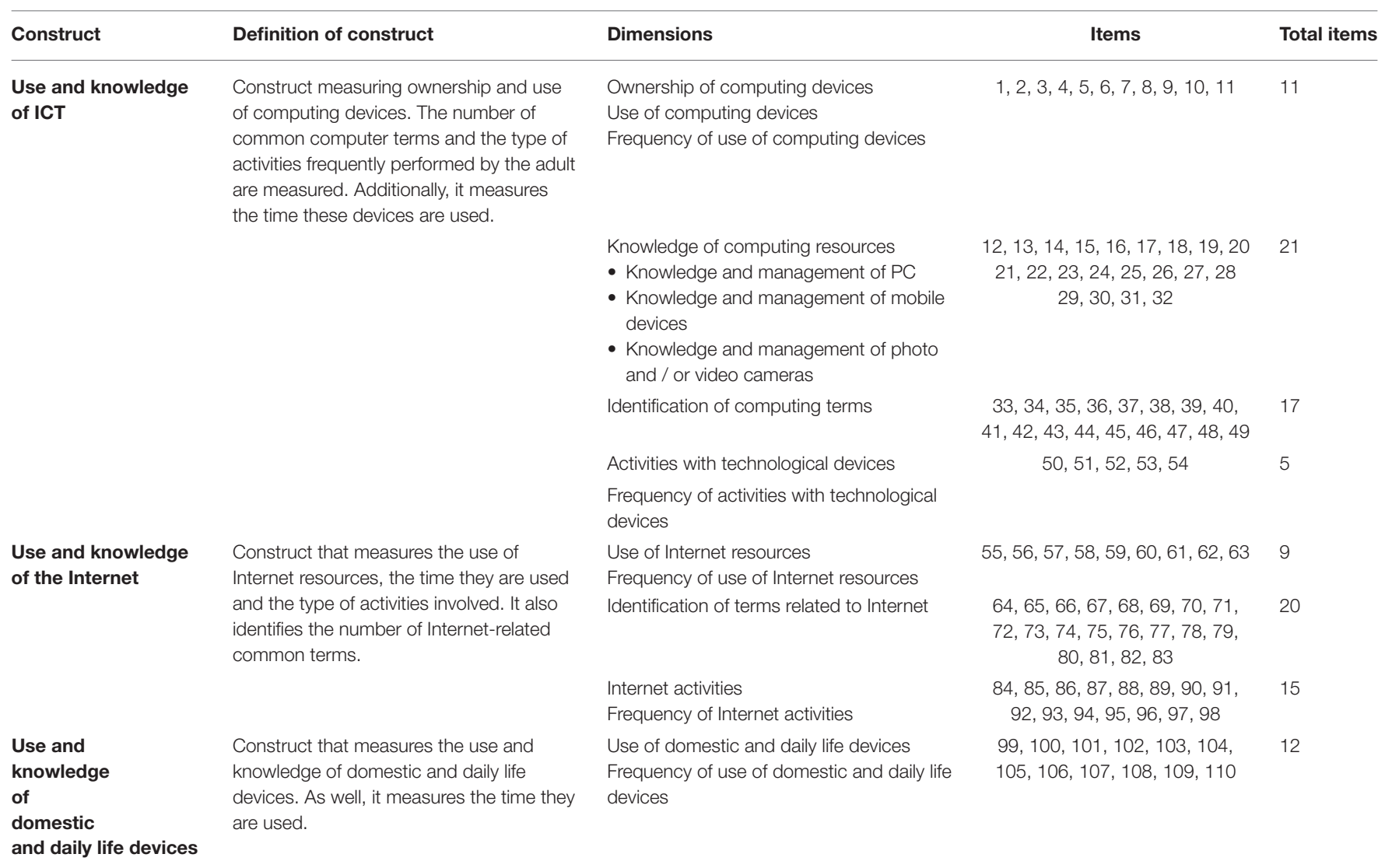

digital competence seemed to be similar. In Figure 3, frequency polygrams of the two groups in both conditions are presented. Both groups had low and low-medium competence at the beginning of the study and after the workshop they increased their digital competence.

The later was confirmed by statistical analysis with MannWhitney $U$ tests when their pre evaluations means were considered $\left[U_{(61,37)}=1,122.5, p<0.96\right]$. Mann-Whitney $U$ tests were again computed and it was evident that, after the workshop, the BLG furthermore increased its digital competence $\left[U_{(61,37)}=810.5, p<0.01\right.$; see Figure 4].

The cumulative number of correct answers on the eight activities was related to the final examination score in a significant way $(r=0.51, p<0.01$; Figure 5).

The number of attempts of the participants in each activity was not associated to the cumulative number of correct answers on the eight activities and the final examination score $(r=0.08$, $p>0.10)$.

\section{Validation of the Blended Workshop}

After the workshops ended, the BLG was invited to answer a validation test that evaluated aspects such as design, usability, and technological acceptance. In the analysis of the first variable, ease of use, 13 of the older adults indicated a positive agreement stating that the interaction with the system is clear and understandable and even the menu is easy to use. For their part, five older adults disagreed that the workshop is easy to use, indicating that a lot of mental effort is required to be able to use the platform and some materials.

In the variable of perceived usefulness, favorable results were obtained from older adults, where 16 stated that it is useful and indispensable to implement this type of workshops so that the population acquires digital literacy skills. Only two adults indicated that they disagreed.

The evaluation of attitude toward using showed that 15 older adults were enthusiastic about using the platform. On the other hand, three adults were neutral and two disagreed. This indicates that the Blended Workshop based on a LMS offers an attractive environment to support older adults to acquire digital skills more easily. However, some aspects of the presentation of materials and access to them must be improved. Finally, in the intention to use variable, 15 older adults indicated a positive agreement stating that they will use the system to reinforce their knowledge during and after the workshop (see Figure 6).

An analysis of comments and experiences of the BLG both by the elderly participants and by the instructor when adopting an online support system for teaching ICT are presented below.

\section{Learning Difficulty}

Despite the fact that older adults are experiencing a decline in their cognitive and perception abilities, according to these results they are able to learn new skills. Also, Navarro et al. (2017), 

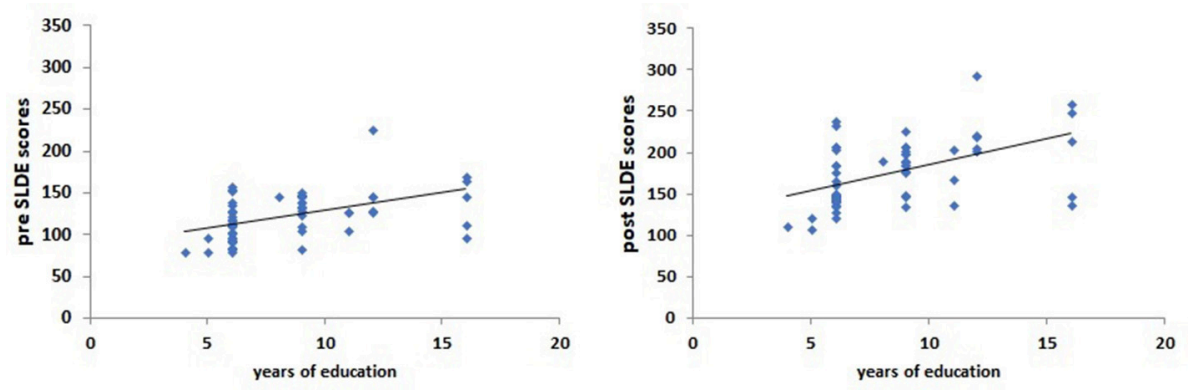

FIGURE 2 | Significant correlations between education and the pre and post scores of the Senior Digital Literacy Evaluation (SDLE) for the Face-to-Face Group (FFG).

\section{Senior Digital Literacy Evaluation}
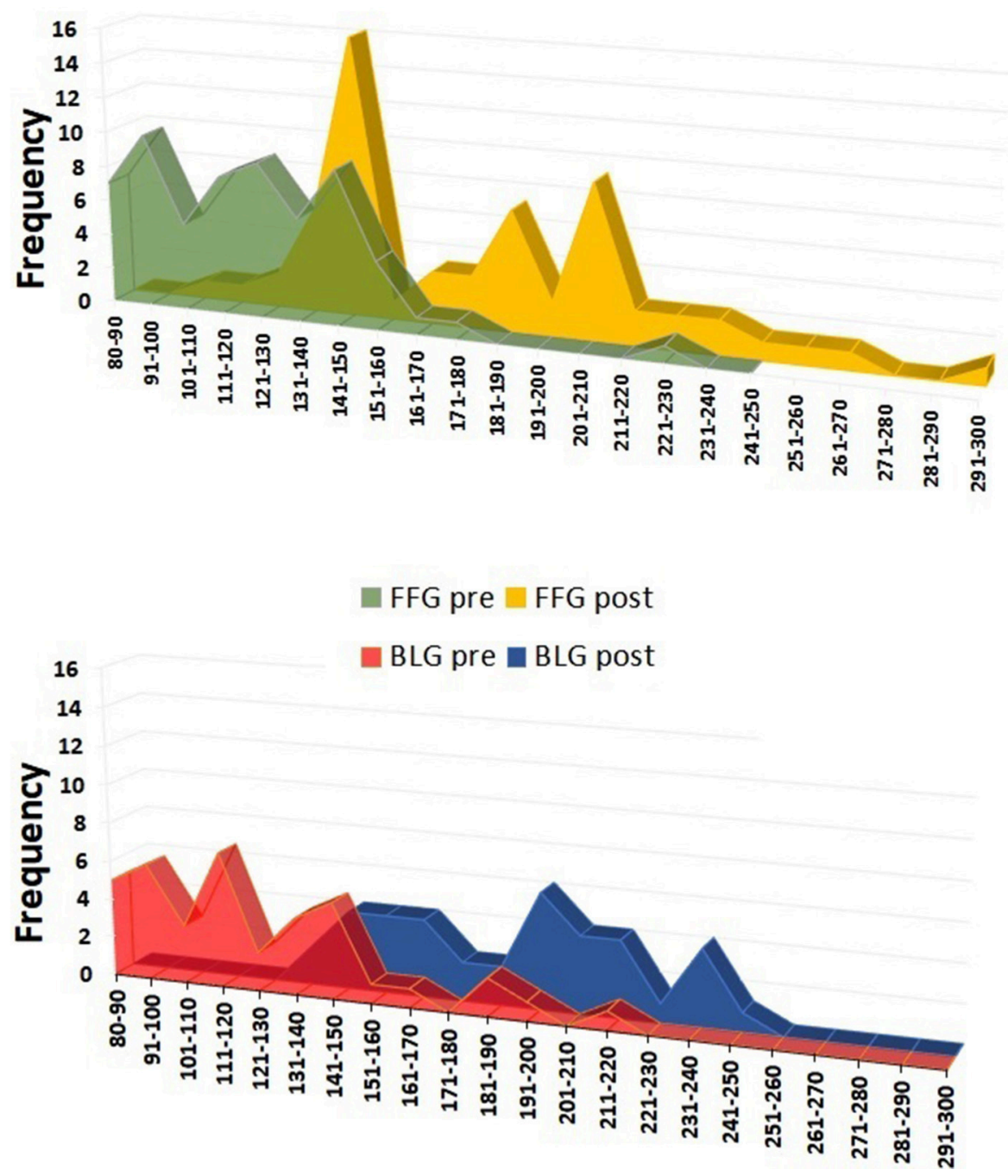

FIGURE 3 | Frequency distributions of the digital literacy of older adults in the Face-to-Face Group and the Blended Learning Group according to the Senior Digital Literacy Evaluation (Cepeda-Rebollar, 2016) before and after the workshops. FFG, Face-to-Face Group, BLG, Blended Learning Group. 


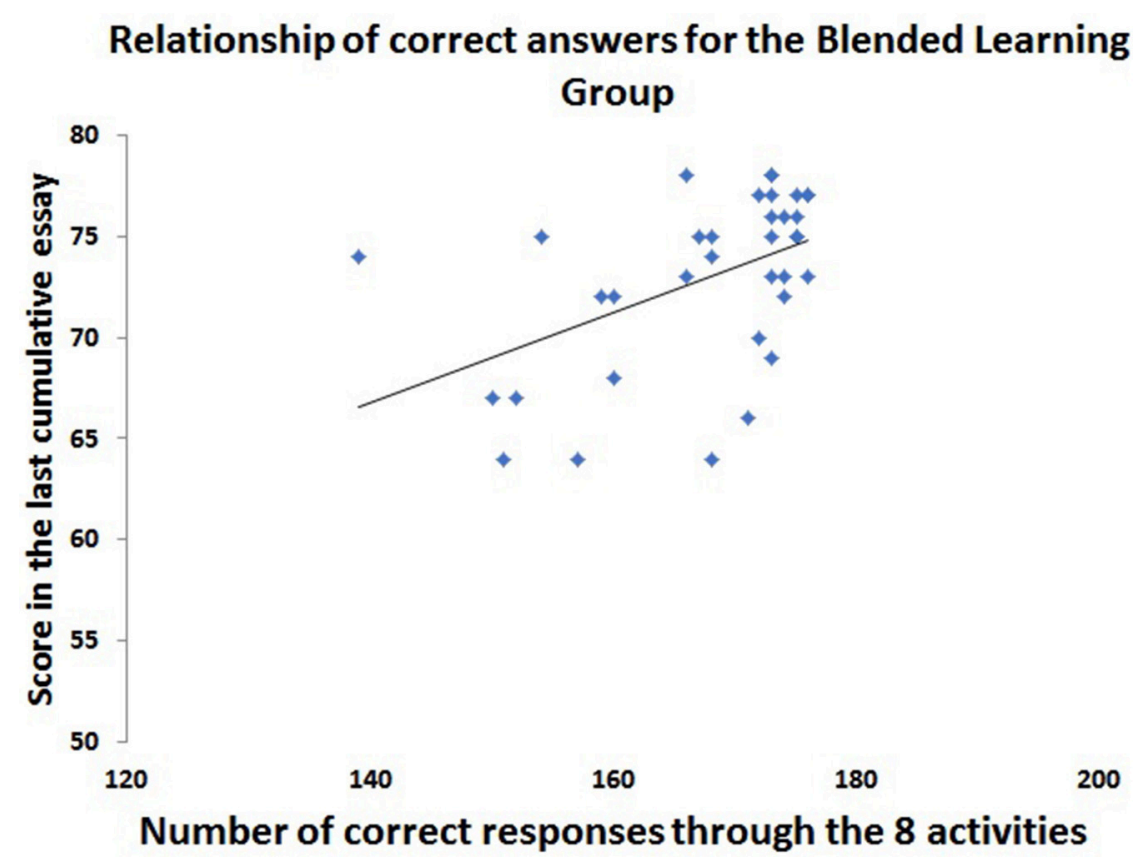

FIGURE 5 | Spearman correlation of the cumulative number of correct answers on the seven activities and the final examination score in the Blended Learning Group, $p<0.01$.

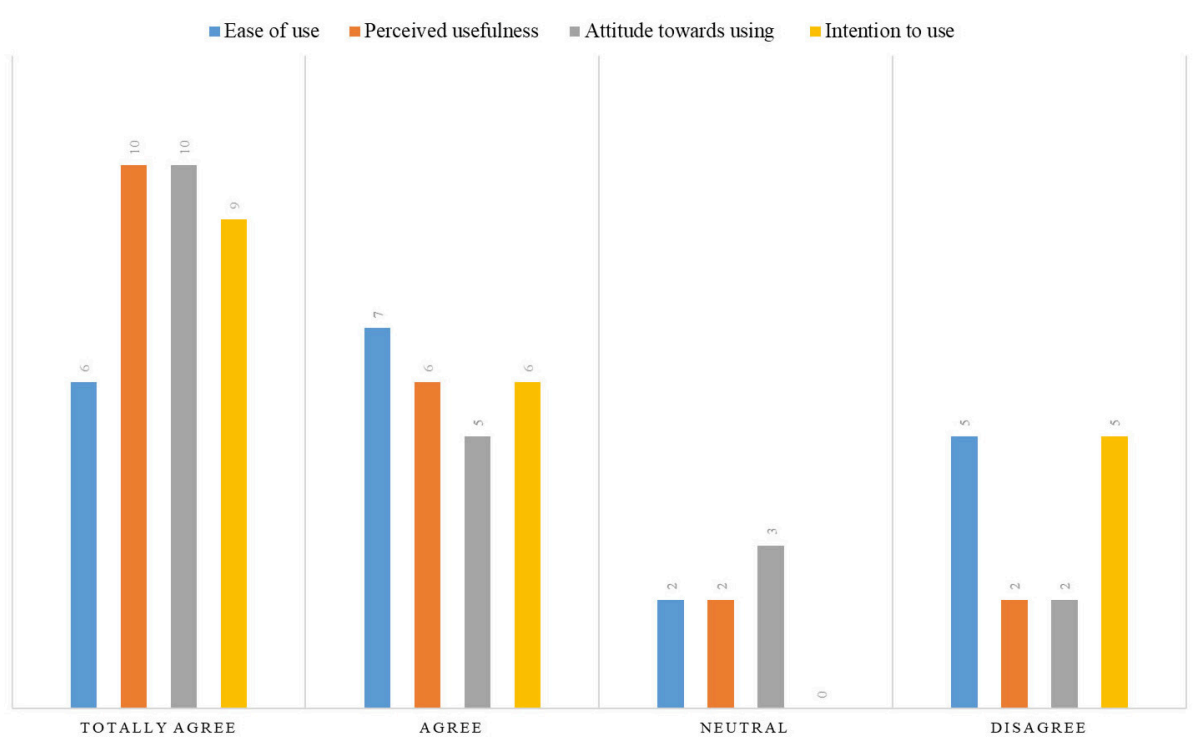

FIGURE 6 | Results of the validation of a Blended Workshop based on a Learning Management System by a group of older adults.

mention that older adults are able to learn and acquire digital skills more easily as long as there is a strong motivation or when they are aware of the functional benefits in relation to ICT.

In this study, participants had the opportunity to explore the blended workshop with the guidance of the instructor and support staff, so they could focus on interacting with the platform and acquiring new knowledge. In addition, it was found that the availability of support and the adults' own confidence influence how they acquire their digital skills.

Regarding the role of the instructor, the difficulty was to design materials and activities that would serve as a review and/or feedback for the topics seen in class, since in the face-to-face workshops adults often forgot some steps to perform certain activities, so they had to be repeated several times for them to 


\section{Senior Digital Literacy Evaluation}

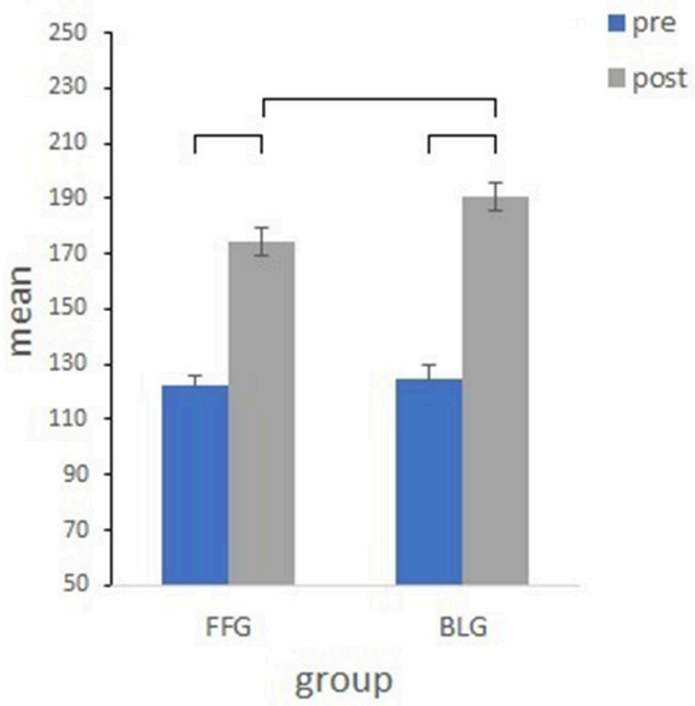

FIGURE 4 | Means and standard errors of the level on the Senior Digital Literacy Evaluation (Cepeda-Rebollar, 2016) before and after the workshops for each group. Brackets point out to significant results according to Wilcoxon $t$-tests within groups $(p<0.001)$ and also to Mann-Whitney $U$ tests between groups $(p<0.01)$. FFG, Face-to-Face Group, BLG, Blended Learning Group.

remember. Derived from this, it was necessary to design materials and activities that would reinforce adult learning.

\section{Usability and User Experience}

Usability is related to the intrinsic characteristics of the system with regard to the user's abilities, perceptions and attitudes. When adults start using the platform, it is clear to them how useful it is.

One of the reasons for having this perception is that the platform was presented in a relaxed and friendly atmosphere without any pressure and clarifying all their doubts when interacting with it. Likewise, some participants mentioned that the blended workshop is a very good idea as long as it is used as a support system, because if it were adopted in a totally asynchronous manner, they would have difficulties using it due to lack of assistance. Some of the interaction difficulties encountered by some participants were:

- Confusion when using digital presentations. The digital presentations were made with a free tool; a limitation of using free software comes because publicity appears below, so some adults mistakenly clicked on it, causing it to open pages they did not want to see. In addition, when clicking on the presentation, it was shown in full screen and some adults did not read the indication to press the Escape key (ESC) and they became anxious when they were not able to leave the presentation.

- Navigation between windows. Some topics show how to perform certain activities step by step. For example, for the "desktop background change" activity adults had to minimize the window where they had opened the blended workshop and performed the steps that were previously shown. This fact showed that for some older adults browsing between windows is something complicated.

- Access to the platform. To access the blended workshop, the user needs to enter a username and password. Adults with no or little knowledge of ICT, sometimes entered some mistaken data and after several attempts they had to change their password. In most cases, it was not because they forgot their access codes, but because they did not type it correctly.

According to the above, it can be observed that the interaction difficulties were due to the inexperience of some older adults in relation to the use of the computer and the Internet. However, the experience of these users was improved, taking into account all their observations and comments, in order to adapt a more usable platform. This entails a challenge that is possible to fulfill, as long as continuous improvements are made based on the experiences of the users.

\section{Strengths of the Workshop Instruction}

One of the strengths of the blended workshop is that it was developed under the guidelines of the ASSURE instructional model, which allowed to know the characteristics of the population, taking into account their visual deficiencies, cognitive and emotional abilities (insecurities). As a result, a space was obtained in which there is an adequate structure and design, attractive text colors and images, quality teaching materials and clear instructions.

The blended workshop also facilitates the learning and acquisition of knowledge by considering the constant and continuous review of each of the topics, in addition to having a learning method where the sequence of the class is organized by initiation, development and closure activities.

\section{DISCUSSION}

The present research combines digital literacy assessment, comparison between face-to-face and blended digital literacy workshops and the validation of the LMS. Previous studies have shown how older adults perceive and use ICT in their daily lives. For example, Schreurs et al. (2017) conducted a study of how older adults perceive their own digital skills, what barriers to digital literacy they face, and what social and institutional support systems they have in place to achieve greater digital literacy. The results of this study indicated that older adults do not have digital skills and that there have limited support systems, which makes it difficult for them to gain experience and comfort with ICT.

Delello and McWhorter (2017) aimed to explore whether ICTs, specifically iPads, improve the lives of older adults. Derived from the results, the authors suggest that the use of the iPad reduced the social isolation of older adults, leading to closer family ties and a greater overall connection to society. In addition, there was also a significant increase in digital skills with respect to the use of the iPad. 
Vroman et al. (2015) analyzed the patterns of ICT use (experience, socio-personal characteristics and use) of older adults living in the New England region. The results showed that most participants use ICT to maintain family connections and to access health information and routine activities. Based on the above, the authors propose a community-centered model that takes into account socio-personal characteristics for future ICT training programs.

Nevertheless, at present there is insufficient documentation on face-to face or blended courses designed for digital competence training of older adults. Moreno Ramírez et al. (2009) and Abad (2014) mention that the courses that currently exist have limitations that affect the learning and understanding of older adults in relation to ICT. For example, face-to-face workshops have numerous groups; this causes distractions between the older adults (Jaggars, 2014). Also, working methods in faceto-face courses are not focused on the particular needs of students (Jaggars, 2014; Margulieux et al., 2016), and do not have availability of learning materials for consulting outside of class (Kemp and Grieve, 2014). This could affect learning in older adults because their cognitive skills decline with age (Davidson and Guthrie, 2017; Meltzer et al., 2017), and they need more stimulation for understanding complex items and concepts.

By contrast, the blended workshops stimulate the use of new ways of learning, build knowledge and cover several limitations presented in face-to-face workshops (Oncu and Cakir, 2011; Chiu and Churchill, 2016; Conole, 2016). The idea of developing an online support tool for digital literacy workshops in this study emerged just to provide a more customized instruction to older adults. Contrary to young students, older adults have clear ideas about what to learn and how. Moreover, blended workshops allow students to have a more active role, as it grants them continued accessibility to study materials. This benefits older adults because they can carry out constant review of the topics and concepts seen in class, avoiding prejudice on those who are not able to attend class periodically for personal reasons or disease. This last point resulted in an opportunity for older adults who participated in blended workshops because they could access to LMS and review the class materials they missed when they were sick or in a medical appointment.

In our study, participants in the blended learning workshops recognized the importance of continued practice and the additional experience provided through the multimedia learning materials added to the LMS. It is also interesting to note that after the end of the digital literacy workshops (both cases), the participating adults not only came forward to ask additional questions, but many also asked "when the next workshop would open."

As part of the analysis in this study, it could be verified that the level of digital competencies of adults raised in both groups, however, the scores in post-evaluations were higher in the BLG group vs. FFG group. This was because adults of BLG group had access to evaluations and information available within the LMS. These evaluations allowed older adults to review the concepts at different times (up to 10 attempts), with the aim of reinforcing the knowledge of certain terms and tasks that were seen in each workshop module. This fact reflected that in the post-evaluations the participants of the blended learning workshop identified more computer terms and carried out more tasks on the Internet than the adults of the classroom workshop. Furthermore, the older adults expressed interest and enthusiasm most of the time because they had a support tool for their learning.

In this case, it can be concluded that the adaptation of blended workshops based on appropriate methodologies, instructional models and teaching-learning models may provide inspiration to more investigations about training the older adult population in any area of knowledge and to enrich the understanding of the background to the topic.

\section{CONCLUSIONS}

For this study it was important to understand the reasons why older adults believe that digital technologies are difficult to use and that some perceive that they are not capable of learning to use them. This understanding is necessary not only to find better ways to introduce digital technologies to currently excluded potential users, but also to improve the design of digital products so that they are easy to use and easy to learn, which can facilitate adoption by all types of users.

Within this study it was possible to implement an adequate blended workshop so that the older adult population could develop their digital skills more easily. Likewise, it is important to take into consideration the experiences and perceptions of older adults in order to adapt and to continue to design both the system and the materials included, so as to present a more usable system.

The proposal of innovative practices, such as the one presented in this study, should make it possible to open up more areas of study to provide older adults with effective intervention strategies to include them digitally, creating spaces that are even adapted to the learning styles of each older adult. One fact to consider is that digital literacy has evolved rapidly from an option into a need, due to the constant change in technology. These constant advances make it insufficient to provide digital literacy to older adults using a single technology. It is therefore important to propose strategies where adults can develop flexible skills and technological self-efficacy to maintain their digital literacy despite the changes and advances.

\section{ETHICS STATEMENT}

This study was carried out in accordance with the recommendations of The Ethics committee of the Instituto de Ciencias de la Salud, Universidad Autónoma del Estado de Hidalgo and it is registered in the Research Directorate with the key UAEH-DI-ICSA-GE-CF-006. All subjects gave written informed consent. The protocol was approved by the Research Directorate of the Universidad Autónoma del Estado de Hidalgo. 


\section{AUTHOR CONTRIBUTIONS}

CM-A and JR-S designed the concept and development of the virtual workshop. AR-L, MA-L, MB-D and JL-N carried out data interpretation and critical review of the study. RC-R, BJ-R and RA-J did bibliographic search, data collection, and capture. CMA drafted the manuscript and received the support of JR-S and AR-L. All authors approved the final version of the manuscript for submission.

\section{ACKNOWLEDGMENTS}

We thank the older adults for their participation in this study. Also, the Instituto de Ciencias de la Salud (ICSa) for access

\section{REFERENCES}

Abad, L. (2014). Design of e-inclusion programs for media literacy of the elderly (Diseño de programas de e-inclusión para alfabetización mediática de personas mayores). Rev. Cientific. Educomun. 21, 173-180. doi: 10.3916/C42-2014-17

Almanasreh, E., Moles, R., and Chen, T. F. (2018). Evaluation of methods used for estimating content validity. Res. Soc. Admin. Pharm. S1551-7411, 30268-7. doi: 10.1016/j.sapharm.2018.03.066

Boarini, M., Cerda, E., and Rocha, S. (2006). The education of the elderly in ICTs. New skills for today's society (La educación de los adultos mayores en TICs. Nuevas competencias para la sociedad de hoy). Rev. Iberoamer. Tecnol. Educ. Educ. Tecnol. 1:7. Available online at: http://sedici.unlp.edu.ar/bitstream/ handle/10915/19198/Documento_completo.pdf?sequence=1

Cabezas, M., Sanchez-Ferreira, M., Casillas Martin, S., and Diogo, F. (2017). Validation of an instrument to measure the digital competence of university students (CODIEU). Rev. Psicol. Educ. 13, A13-022-A13-024. doi: 10.17979/reipe.2017.0.13.2180

Cepeda-Rebollar, R. M. (2016). Impact of Digital Literacy on Adults Over 60 Years of Age of the Centro Gerontológico Integral de Punta Azul od Pachuca de Soto, Hidalgo. Bachelor thesis. Universidad Autónoma del Estado de Hidalgo. Mexico

Chiu, T., and Churchill, D. (2016). Design of learning objects for concept learning: effects of multimedia learning principles and an instructional approach. Interact. Learn. Environ. 24, 1355-1370. doi: 10.1080/10494820.2015.10 06237

Choi, N., and DiNitto, D. (2013). The digital divide among low-income homebound older adults: internet use patterns, ehealth literacy, and attitudes toward computer/internet use. J. Med. Internet Res. 15:e93. doi: 10.2196/jmir.2645

Community Grants Hub (2017). Digital Literacy for Older Australians: National Network Manager. Australian Government. Available online at: https://www. communitygrants.gov.au/sites/default/files/documents/06_2017/2017-940_-_ dloa_-_nnm_-_generic_feedback.pdf

Conole, G. (2016). MOOCs as disruptive technologies : strategies for enhancing the learner experience and quality of MOOCs Los MOOC como tecnologías disruptivas : estrategias para mejorar la experiencia de aprendizaje y la calidad de los MOOC. Rev. Educ. Distanc. 50, 1-18. doi: 10.6018/red/50/2

Consejo Nacional de Población (CONAPO) (2010). Proyecciones de Población de México 2000-2050. México.

Davidson, J. G., and Guthrie, D. M. (2017). Older adults with a combination of vision and hearing impairment experience higher rates of cognitive impairment, functional dependence, and worse outcomes across a set of quality indicators. J. Aging Health 1:898264317723407. doi: $10.1177 / 0898264317723407$

Delello, J. A., and McWhorter, R. R. (2017). Reducing the digital divide: connecting older adults to iPad technology. J. Appl. Gerontol. 36, 3-28. doi: $10.1177 / 0733464815589985$ to computer rooms. Also, we thank Monzerrat Cepeda for the authorization to use her statistical data of her Bachelor's thesis Impact of digital literacy in adults over 60 years of the Centro Gerontológico Integral de Punta Azul de Pachuca de Soto, Hidalgo. Finally, we thank Reyna Lopez-Blé for the revision of the English language version. This publication was financed with resources PRODEP 2018.

\section{SUPPLEMENTARY MATERIAL}

The Supplementary Material for this article can be found online at: https://www.frontiersin.org/articles/10.3389/fict.2018. 00021/full\#supplementary-material

Engel, A., Salvador, C., and Membrive, A. (2018). Information and communication technologies and students' out-of-school learning experiences. Digital Educ. Rev. 33, 130-149. Available online at: http://revistes.ub.edu/index.php/der/ article/view/21689/pdf

Fausset, C. B., Harley, L., Farmer, S., and Fain, B. (2013). “Older adults' perceptions and use of technology: a novel approach," in International Conference on Universal Access in Human-Computer Interaction, Vol. pt. II. (Berlin; Heidelberg: Springer), 51-58.

Friemel, T. N. (2016). The digital divide has grown old: determinants of a digital divide among seniors. New Media Soc. 18, 313-331. doi: $10.1177 / 1461444814538648$

Gonzalez, A., Ramirez, M. P., and Viadel, V. (2015). ICT learning by older adults and their attitudes toward computer use. Curr. Gerontol. Geriatr. Res. 2015:849308. doi: 10.1155/2015/849308

Hall, R., Atkins, L., and Fraser, J. (2014). Defining a self-evaluation digital literacy framework for secondary educators: the DigiLit Leicester project. Res. Learn. Technol. 22:21440. doi: 10.3402/rlt.v22.21440

Hodge, H., Carson, D., Carson, D., Newman, L., and Garrett, J. (2017). Using Internet technologies in rural communities to access services: the views of older people and service providers. J. Rural Stud. 54, 469-478. doi: 10.1016/j.jrurstud.2016.06.016

Instituto Nacional de Estadistica y Geografía (National Institute of Statistics and Geography) (2016). INEGI.

Internet World Stats (2017). Central America Internet Usage and Population Statistics. Available online at: http://www.internetworldstats.com/stats2.htm

Jaggars, S. (2014). Choosing between online and face-to-face courses: community college student voices. Am. J. Dist. Educ. 28, 27-38. doi: 10.1080/08923647.2014.867697

Kemp, N., and Grieve, R. (2014). Face-to-face or face-to-screen? Undergraduates' opinions and test performance in classroom vs. Online learning. Front. Psychol. 5:1278. doi: 10.3389/fpsyg.2014.01278

Kuerbis, A., Mulliken, A., Muench, F., Moore, A. A., and Gardner, D. (2017) Older adults and mobile technology: factors that enhance and inhibit utilization in the context of behavioral health. Mental Health Addict. Res. 2:136. doi: 10.15761/MHAR.1000136

Lopez-Betancourt, A., and Garcia Rodriguez, M. L. (2015). "An application of ASSURE model to solve contextual problems in virtual classroom," in in Proceedings of E-Learn: World Conference on E-Learning in Corporate, Government, Healthcare, and Higher Education (1332-1336). Available online at: https://www.learntechlib.org/p/161834

Margulieux, L. E., McCracken, W. M., and Catrambone, R. (2016). A taxonomy to define courses that mix face-to-face and online learning. Educ. Res. Rev. 19, 104-118. doi: 10.1016/j.edurev.2016.07.001

Meltzer, E. P., Kapoor, A., Fogel, J., Elbulok-Charcape, M. M., Roth, R. M., Katz, M. J., et al. (2017). Association of psychological, cognitive, and functional variables with self-reported executive functioning in a sample of nondemented community-dwelling older adults. 
Appl. Neuropsychol. 24, 364-375. doi: 10.1080/23279095.2016.11 85428

Moreno Ramírez, H. B., Manrique Rojas, E., Sevilla Caro, M., and Ramírez Ramírez, M. (2009). Management of the Learning of New Technologies in Adults of the Elderly (Gestión del Aprendizaje de las Nuevas Tecnologías en Adultos de la Tercera Edad), 102-111.

Muchtar, H. S., and Yanuarsari, R. (2018). The Implementation of andragogy approach in learning interaction. GSTF J. Educ. 4, 1-4. Available online at: http://dl6.globalstf.org/index.php/jed/article/view/1281

Navarro, J. L. A., López Ruiz, V. R., and Nevado Peña, D. (2017). The effect of ICT use and capability on knowledge-based cities. Cities 60A, 272-280. doi: $10.1016 /$ j.cities.2016.09.010

Oliver, A., Tomás, J. M., and Montoro-Rodriguez, J. (2017). Dispositional hope and life satisfaction among older adults attending lifelong learning programs. Arch. Gerontol. Geriatr. 72, 80-85. doi: 10.1016/j.archger.2017.05.008

Oncu, S., and Cakir, H. (2011). Research in online learning environments: priorities and methodologies. Comput. Educ. 57, 1098-1108. doi: 10.1016/j.compedu.2010.12.009

Ordoñez, T., Cachioni, M., and Sanches Yassuda, M. (2010). Elderly online: effects of a digital inclusion program in cognitive performance. Arch. Gerontol. Geriatr. 53, 216-219. doi: 10.1016/j.archger.2010.11.007

Queiruga-Dios, A., Izard-Anaya, E., Bullón-Pérez, J. J., Hernández-Encinas, A., and Martín-Vaquero, J. (2015). Case study: online learning for design and calculation of machines. Front. ICT 2, 1-8. doi: 10.3389/fict.2015. 00027

Rangel, A., and Peñalosa, E. A. (2013). Digital literacy in higher education professors: construction and empirical test of an assesment instrument. Rev. Med. Educ. 4, 31-33. doi: 10.12795/pixelbit.2013.i43.01

Rubenson, K. (2018). "Conceptualizing participation in adult learning and education: equity issues," in The Palgrave International Handbook on Adult and Lifelong Education and Learning (London: Palgrave Macmillan), 337-357.

Schejter, A., Ben Harush, O. R., and Tirosh, N. (2015). "Re-theorizing the "digital divide": identifying dimensions of social exclusion in contemporary media technologies," in In FACE Conference: European Media Policy 2015: New Contexts, New Approaches (University of Helsinki, Finland).

Schreurs, K., Quan-Haase, A., and Martin, K. (2017). Problematizing the digital literacy paradox in the context of older adults' ICT use: aging, media discourse, and self-determination. Can. J. Commun. 42. doi: 10.22230/cjc.2017v42n2a3130
Tam, M. (2018). "Lifelong learning for older adults: culture and confucianism," in The Palgrave International Handbook on Adult and Lifelong Education and Learning (London: Palgrave Macmillan), 857-878.

Tennant, B., Stellefson, M., Dodd, V., Chaney, B., Chaney, D., Paige, S., et al. (2015). eHealth literacy and web 2.0 health information seeking behaviors among baby boomers and older adults. J. Med. Internet Res. 17:e70. doi: 10.2196/jmir.3992

Tsai, S. H., Shillair, R., and Cotten, S. R. (2015). Social support and "playing around" an examination of how older adults acquire digital literacy with tablet computers. J. Appl. Gerontol. 36, 29-55. doi: 10.1177/0733464815609440

van Deursen, A. J., and Helsper, E. J. (2015). A nuanced understanding of Internet use and non-use among the elderly. Eur. J. Commun. 30, 171-187. doi: $10.1177 / 0267323115578059$

Van Deursen, A. J., Helsper, E. J., and Eynon, R. (2016). Development and validation of the Internet Skills Scale (ISS). Inform. Commun. Soc. 19, 804-823. doi: 10.1080/1369118X.2015.1078834

Vas Patricio, M. R., and Osorio, A. J. (2011). "Lifelong learning, intergenerational relationships and ICT: perceptions of children and older adults,"in Elderly, Education, Intergenetarional Relationship and Social Development, Proceedings of 2nd Conference of ELOA (Braga).

Vroman, K. G., Arthanat, S., and Lysack, C. (2015). "Who over 65 is online?" Older adults' dispositions toward information communication technology. Comput. Human Behav. 43, 156-166. doi: 10.1016/j.chb.2014. 10.018

Wlodkowsk, R. J., and Ginsberg, M. B. (2017). Enhancing Adult Motivation to Learn: A Comprehensive Guide for Teaching All Adults. páginas. USA: John Wiley \& Sons, 512

Conflict of Interest Statement: The authors declare that the research was conducted in the absence of any commercial or financial relationships that could be construed as a potential conflict of interest.

Copyright ( 2018 Martínez-Alcalá, Rosales-Lagarde, Alonso-Lavernia, RamírezSalvador, Jiménez-Rodríguez, Cepeda-Rebollar, López-Noguerola, Bautista-Díaz and Agis-Juárez. This is an open-access article distributed under the terms of the Creative Commons Attribution License (CC BY). The use, distribution or reproduction in other forums is permitted, provided the original author(s) and the copyright owner(s) are credited and that the original publication in this journal is cited, in accordance with accepted academic practice. No use, distribution or reproduction is permitted which does not comply with these terms. 